\title{
Penerapan Metode Dempster Shafer Untuk Sistem Deteksi Gangguan Kecemasan Obsessive Compulsive Disorder Berbasis Web
}

\author{
Nidia Enjelita Saragih*, Robiatul Adawiyah \\ Fakultas Teknik dan Ilmu Komputer, Universitas Potensi Utama, Medan, Indonesia \\ Email: 1," nidia.1924@gmail.com, ${ }^{2}$ robiatulbintisyarifudin@gmail.com \\ Email Penulis Korespondensi: nidia.1924@gmail.com
}

\begin{abstract}
Abstrak-Obsessive Compulsive Disorderatau OCD merupakan bagian dari gangguan kecemasan yang membuat penderitanya menghabiskan banyak waktu untuk melakukan hal yang sama berulang-ulang, sehingga menyebabkan stress dan memburuknya kehidupan sehari-hari. Gangguan kecemasan ini bisa menjadi semakin parah jika penderita tidak menyadari dan segera mendapat bantuan psikolog. Sebuah sistem pakar diagnosa OCD dapat menjadi langkah awal deteksi agar penanganan terhadap gangguan ini bisa dilakukan sesegera mungkin. Implementasi metode Dempster Shafer pada sistem pakar yang dihasilkan dari penelitian ini mampu menghasilkan nilai persentasi kemungkinan seseorang mengidap OCD berdasarkan gejala yang diinputkan pengguna. Jika nilai persentasi yang didapatkan lebih dari \&0\%, maka pengguna disarankan untuk mendapatkan penanganan dari seorang psikolog sebelum gangguan menjadi semakin parah. Sistem yang dibangun berbasis web sehingga mudah diakses oleh masyarakat.
\end{abstract}

Kata Kunci: Obsessive Compulsive Disorder; Gangguan Kecemasan; Sistem Pakar; Dempster Shafer

\begin{abstract}
Obsessive Compulsive disorder or OCD is a type of anxiety disorder that makes someone wasting so much time in doing the same things reccurently. it cause distress and significant impairment. This anxiety disorder will becoming worse if someone didn't realize and get psychologist help. An expert system that diagnose OCD would be the initial step of detection, so this disorder can be handled sooner. By implementing Dempster Shafer method, this expert system produce percentage value of someone having this disorder, based on the inputted symptons. If the result more than $60 \%$, the user need a psychologist's treatment before it coming worse. The system is web based, so it is handy to access.
\end{abstract}

Keywords: Obsessive Compulsive Disorder; Anxiety Disorder; Expert System; Dempster Shafer

\section{PENDAHULUAN}

Kecemasan dalam tingkat tertentu dapat membuat seseorang menjadi lebih produktif. Misal,ketika seseorang merasa cemas tidak dapat menyelesaikan tugasnya, maka ia akan berusaha semaksimal mungkin untuk menyelesaikannyadan mengumpulkannya tepat waktu agar dapat terhindar dari cemas yang lebih berat.Perasaan cemas yang disebutkan diatas bukanlah menjadi suatu masalah, cemas akan menjadi masalah apabila perasaan itu begitu mengganggu sampai menghambat seseorangdalam melakukan aktifitasnya[1]. Perasaan cemas yangberlebihan inilah yang perlupenanganan dan pemecahan praktis agar ia dapat melakukan aktifitasseperti biasa dan mencapaikehidupan efektif sehari-hari[2].

Gangguan kecemasan atau disebut sebagai anxiety neurosis atau disebut juganeurosa kecemasan merupakan bentuk neurosa dengan gejala palingmencolok ialah ketakutan yang terus menerus terhadap bahaya yangseolah-olah terus mengancam, yang sebenarnya tidak nyata tetapihanya ada dalam perasaan penderitanya saja. Kecemasan merupakan manifestasi dari berbagai proses yang bercampurbaur yang terjadi ketika orang sedang mengalami tekanan perasaan(frustasi) dan pertentangan batin (konflik). Kecemasan itu mempunyaisegi yang disadari yaitu seperti rasa takut, terkejut, tidak berdaya, rasaberdosa atau bersalah, terancam dan sebagainya[3].

Terdapat beberapa tipe gangguan kecemasan, antara lain social phobia, agoraphobia, panic disorder, generalized anxiety disorder, post traumatic stress disorder, dan Obsessive Compulsive Disorder[4].Gangguan obsesif kompulsifmerupakan salah satu gangguan yangpaling sulit ditangani[5]. Pada gangguan ini, penderita mengalami munculnya pemikiran yang sama secara berulang-ulang yang cukup mengganggu.

Pada dasarnya setiap orang pernah memiliki pemikiran yang negatif atau mengganggu. Dari suatu studi ditemukan bahwa $84 \%$ orang normal melaporkan pernah memiliki pemikiran-pemikiran yang terus berulang dan mengganggu. Yang membedakan dengan orang yang mengalami gangguan obsesif-kompulsif adalah bahwa orang-orang yang "normal" akan mampu menghentikan pemikiran-pemikiran negatif tersebut sehingga tidak sampai mengganggu dirinya; sedangkan penderita gangguan obsesif-kompulsif tidaklah demikian[6].

Obsesif adalah suatu pikiran yang terus-menerus secarapatologis muncul dalam diri seseorang,bayangan (image), gagasan, atau impuls-impulsyang menetap (terus-menerus) yang dirasakanindividu mengganggu hingga kesadarannyakehilangan kontrol dan secara signifikanmenyebabkananxiety dan distress. Kompulsifadalah tindakan yang didorong impuls yangberulang kali dilakukan, pengulangan perilakuatau tindakan mental di mana individumerasa harus melakukannya.

Gangguan ini dapat menyerang anak-anakataupun orang yang baru menginjakdewasa. OCD sering dimulai ketika seseorang masih dalam usia muda. Puncak usia daripermulaan serangan bagi laki-laki adalahantara 6-15 tahun dan untuk perempuanadalah usia 20-29 tahun [7].

Penderita obsessive- kompulsif bisa menghabiskan banyak waktu dalam setiap harinya untuk melakukan hal yang sama berulang-ulang. Seperti berulangkali mengecek pintu, saluran gas, mencuci tangan, dan kegiatan 
lain. Perilaku repetitif ini dilakukan penderita dengan tujuan mengurangi ketegangan yangdihasilkan pikiranpikiran obsesif atau untukmencegah terjadinya suatu bencana[5].

Pada umumnya penderita OCD mengalami gejala yang relatif sama. Namun, observasi gejala lanjutan akan mengantarkan pada beberapa klasifikasi dari gangguan kecemasan ini. Seperti misalnya subjek yang mencuci tangan ketika mau makan hingga menghabiskan waktu 15 menit, dan mandi membutuhkan waktu hingga hampir 1 jam.Ada pula ditemui kasus subjek yang 'harus' memeriksa kunci pintu hingga 11 kali sebelum tidur . Dan subjek F yang sangat lama memulai mencatat, karena garis bantu yang dibuat di sebelah kiri belum juga lurus sebagaimana yang diinginkan[8].Berdasarkan kemunculan gejala di atas, secara garis besar ada 3 tipe OCD yakni washing, checking, dan counting.

Deteksi dini terhadap keberadaan gangguan ini dapat mempermudah penanganannya oleh psikolog. Karena itu dibutuhkan sebuah sistem pakar yang dapat membantu mendiagnosa OCD pada seseorang. Sistem pakar adalah sistem yang mampu menirukan penalaran seorang pakar komputer dapat menyelesaikan masalah yang seperti biasa dilakukan oleh para ahli[9]. Sistem pakar mampu menyimpan pengetahuan yang dimiliki pakar untuk menghasilkan keputusan atau analisa layaknya pakar. Sistem pakar telah banyak digunakan dalam berbagai bidang keilmuan, seperti kesehatan, teknik mesin, maupun bidang lainnya.

Pada penelitian ini, sistem mengadopsi pengetahuan/kepakaran psikolog dalam mendeteksi keberadaan OCD berdasarkan gejala yang dialami oleh pengguna. Beberapa pertanyaan seputar gejala OCD akan diajukan kepada pengguna yang harus dijawab dengan jawaban ya atau tidak. Setiap jawaban akan mengantarkan pada kesimpulan deteksi OCD dari pengguna tersebut. Kemampuan sistem pakar dalam mendiagnosis suatu gejala memang tidak sebaik seorang dokter ahli, masih banyak hal yang tidak pasti atau tidak konsisten yang dapat menyebabkan kemungkinan kesalahan diagnosis. Ketidak konsistenan ini dapat menyebabkan ketidakpastian hasil diagnosis sistem dan menjadi sebuah pertanyaan baru tentang besarnya persentasi kepastian hasil tersebut. Perhitungan ketidakpastian sangat diperlukan dalam system pakar, agar hasil diagnosis dapat mendekati diagnosis seorang pakar atau ahli. Metode Perhitungan ketidakpastian sistem pakar dapat dilakukan dengan beberapa metode, salah satu metode yang dapat digunakan adalah metode Demspter Shafer[10].

Metode Dempster Shafer memiliki beberapa karakteristik yang secara instuitif sesuai dengan cara berfikir seorang pakar, namun dengan dasar matematika yang kuat[11]. Beberapa penelitian di bidang sistem pakar telah dilakukan sebelumnya. Seperti yang dilakukan oleh Mikha Dayan Sinaga tentang implementasi Dempster Shafer dalam mendeteksi penyakit akibat bakteri Salmonella. Dalam penelitian tersebut, penulis menyimpulkan bahwa metode Dempster Shafer mampu memberikan rekomendasi perhitungan yang akurat untuk dapat dijadikan referensi ketepatan diagnosa untuk mendeteksi penyakit dari akibat Bakteri Salmonella[11]. Penelitian lain dilakukan oleh Silvia Angelia Gozali tentang implementasi metode Dempster Shafer untuk deteksi penyakit mental skizofrenia dan psikotik. Penerapan metode Dampster Shafer dalam mendeteksi gejala Mental Disorder tipologi Skizofrenia dan Psikotik berhasil memberikan hasil yang tepat. Interaksi melalui aplikasi berbasis web sangat memudahkan pengguna dalam memahami dan mengetahui gejala Mental Disorder[12].

Dengan menerapkan metode Dempster Shafer dalam diagnosa OCD, sistem diharapkan mampu memberikan nilai persentasi kemungkinan mengidap OCD berdasarkan penelusuran gejala yang dialami oleh seseorang.

\section{METODOLOGI PENELITIAN}

\subsection{Tahapan Penelitian}

Adapun tahapan yang digunakan dalam penelitian ini, terlihat pada gambar berikut :

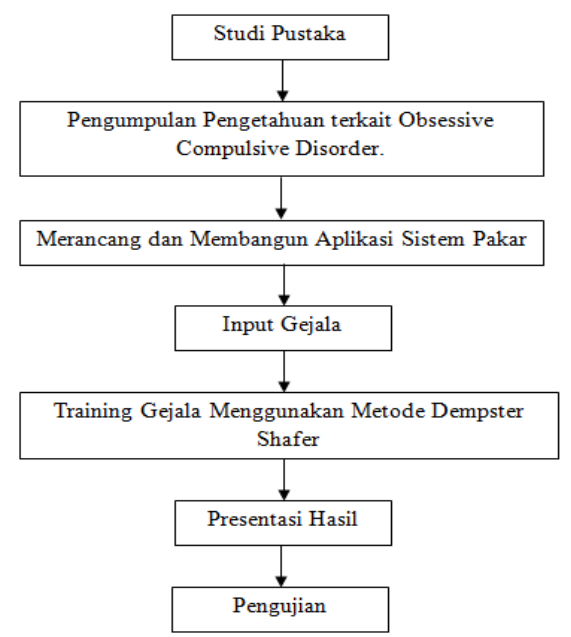

Gambar 1. Tahapan Penelitian 
a) Studi Pustaka

Pengambilan data dari buku, e-journal, dan sumber-sumber lain yang berhubungan dengan permasalahan yang akan diteliti beserta metode yang bisa dijadikan sebagai solusi.

b) Pengumpulan Pengetahuan

Pada tahap ini, penulis mengumpulkan informasi terkait Obsessive Compulsive Disorder. Pengetahuan yang dimaksud termasuk data gejala yang umum dialami oleh penderita OCD dengan melakukan wawancara dengan pakar, dalam hal ini adalah seorang psikolog. Wawancara ini dilakukan pada biro psikologi Minauli Consult, Medan. Data yang didapat disajikan pada bagian dataset.

c) Merancang dan Membangun Aplikasi Sistem Pakar

Selanjutnya peneliti merancang sistem utuh yang menerapkan metode Dempster Shafer. Dempster-Shafer adalah suatu teori matematika untuk pembuktian berdasarkan belief functions and plausible reasoning (fungsi kepercayaan dan pemikiran yang masuk akal), yang digunakan untuk mengkombinasikan potongan informasi yang terpisah (bukti) untuk mengkalkulasi kemungkinan dari suatu peristiwa [13].

Belief (Bel) adalah ukuran kekuatan evidence (bukti) dalam mendukung suatu himpunan proposisi. Jika bernilai 0 maka mengindikasikan bahwa tidak ada evidence, dan jika bernilai 1 menunjukkan adanya kepastian atau Plausability (Pl). Plausibility dinotasikan sebagai berikut

$$
\operatorname{Pl}(s): 1-\operatorname{Bel}(-s)
$$

Plausability juga bernilai 0 sampai 1. Jika kita yakin -s, maka dapat dikatakan bahwa "Bel=(-s)=0". Pada teorema Dempster-Shafer kita mengenal adanya frame of discernment yang dinotasikan dengan " $\theta$ ". Frame inimerupakansemesta pembicaraan dari sekumpulan hipotesis sehingga sering disebut dengan environment.

Dimana :

$$
\theta=\{\theta 1, \theta 2, \ldots \theta n\}
$$

$\theta$

$=$ Frame of discernment atau environment

$\theta 1, \theta 2, \ldots \theta \mathrm{n}=$ elemen $/$ unsur bagian dalam environment

Andaikan diketahui $\mathrm{X}$ adalah subset dari $\theta$, dengan $\mathrm{m}_{1}$ sebagai fungsi densitas, dan $\mathrm{Y}$ juga merupakan subset dari $\theta$ dengan $\mathrm{m}_{2}$ sebagai fungsi densitasnya, maka kita dapat membentuk fungsi kombinasi $\mathrm{m}_{1}$ dan $\mathrm{m}_{2}$ sebagai $\mathrm{m}_{3}$, yaitu:

$$
\mathrm{m} 3(\mathrm{Z})=\frac{\sum X \cap Y=Z m 1 X \cdot m 2(Y)}{1-\sum \quad X \cap Y=\varnothing m 1 X \cdot m 2(Y)}
$$

Implementasi metode Dempster Shafer dilakukan dengan menggunakan bahasa pemrograman PHP. PHP dikatakan sebagai sebuah server-side embedded script language artinya sintaks-sintaks dan perintah yang kita berikan akan sepenuhnya dijalankan oleh server tetapi disertakan pada halaman HTML biasa. Aplikasi-aplikasi yang dibangun oleh PHP pada umumnya akan memberikan hasil pada web browser, tetapi prosesnya secara keseluruhan dijalankan di server [14].

World Wide Web (Biasa disingkat WWW) atau web adalah salah satu dari sekian banyak layanan yang ada di internet. Layanan ini paling banyak digunakan di internet untuk menyampaikan informasi karena sifatnya mendukung multimedia. Artinya informasi tidak hanya disampaikan melalui teks, tapi juga gambar, video dan suara [15].

d) Input Gejala

Data gejala yang didapatkan pada tahapan pengumpulan pengetahuan sebelumnya, diinputkan ke dalam sistem. Nilai bobot pada setiap gejala akan dikomputasikan dengan metode Dempster Shafer.

e) Training Gejala Menggunakan metode Dempster Shafe

Pada tahapan ini, peneliti akan melakukan simulasi jalannya sistem. Pertanyaan-pertanyaan yang diajukan oleh sistem akan diinput jawabannya untuk mendapatkan presentasi hasil berdasarkan sistem.

f) Presentasi Hasil

Berdasarkan input jawaban atas pertanyaan yang diajukan sistem, sistem akan melakukan perhitungan terhadap nilai bobot dengan menggunakan metode Dempster Shafer. Perhitungan ini menghasilkan nilai presentasi indikasi OCD. Hasil yang didapat ditampilkan pada sistem pakar.

g) Pengujian

Langkah terakhir adalah pengujian cross check (verifikasi pakar) dengan cara membandingkan hasil yang diperoleh dari sistem dengan pengetahuan yang dimiliki pakar. Beberapa simulasi dijalankan untuk menguji kesesuaian antara hasil sistem dengan analisa pakar.

\subsection{Dataset}

Dataset yang digunakan pada penelitian ini yaitu data gejala yang didapatkan dari studi pustaka dan wawancara dengan psikolog pada biro psikologi Minauli Consult, Medan. Rincian data terlihat pada tabel berikut: 
JURNAL MEDIA INFORMATIKA BUDIDARMA

Volume 5, Nomor 1, Januari 2021, Page 48-57

ISSN 2614-5278 (media cetak), ISSN 2548-8368 (media online)

Available Online at https://ejurnal.stmik-budidarma.ac.id/index.php/mib

DOI 10.30865/mib.v5i1.2533

Tabel 1. Klasifikasi Obsessive Compulsive disorder

\begin{tabular}{lll}
\hline No & Nama Tipe & Kode \\
\hline 1 & Washing & W \\
2 & Checking & C \\
3 & Counting & O \\
\hline
\end{tabular}

Adapun gejala yang umumnya dialami penderita OCD dijelaskan pada tabel 2.

Tabel 2. Data Gejala

\begin{tabular}{|c|c|}
\hline Kode & Gejala \\
\hline G01 & Muncul dorongan untuk melakukan suatu kegiatan berulang-ulang. \\
\hline G02 & Terganggunya rutinitas normal \\
\hline G03 & Memburuknya hubungan sosial \\
\hline G04 & $\begin{array}{l}\text { Munculnya dorongan, kekhawatiran, dan bayangan-bayangan yang terus } \\
\text { mengganggu yang menyebabkan kegelisahan }\end{array}$ \\
\hline G05 & Kecemasan yang muncul berasal dari dalam diri, bukan pengaruh dari luar \\
\hline G06 & Tidak sedang berada di bawah pengaruh obat-obatan \\
\hline G07 & $\begin{array}{l}\text { Berusaha menekan atau menghilangkan gangguan kecemasan dengan melakukan } \\
\text { kegiatan berulang }\end{array}$ \\
\hline G08 & $\begin{array}{l}\text { Perbuatan berulang yang dilakukan bukan untuk memperoleh kepuasan. Tetapi } \\
\text { hanya untuk mengurangi penderitaan akibat rasa cemas yang terus muncul }\end{array}$ \\
\hline G09 & Menghabiskan waktu lebih dari satu jam untuk melakukan hal yang berulang \\
\hline G10 & $\begin{array}{l}\text { Berusaha menghindari tempat-tempat yang memicu munculnya obsesi (misalnya } \\
\text { menghindari berjabat tangan, menghindari ke toilet umum). }\end{array}$ \\
\hline G11 & $\begin{array}{l}\text { Muncul dorongan agresif yang mengerikan( misalnya melukai anak-anak atau } \\
\text { berteriak di tempat ibadah) }\end{array}$ \\
\hline G12 & $\begin{array}{l}\text { Muncul kebutuhan untuk memastikan segala benda dalam kondisi khusus(misalnya } \\
\text { susunan benda mesti simetris, dan berjumlah genap/ganjil) }\end{array}$ \\
\hline G13 & Meyakini bahwa dirinya terkontaminasi oleh orang lain \\
\hline G14 & Terus menerus mencuci tangan \\
\hline G15 & Terus-menerus mengecek kompor atau tabung gas \\
\hline G16 & Terus-menerus mengecek kunci pintu \\
\hline G17 & Mengecek suatu pekerjaan secara berulang \\
\hline G18 & Berpikir bahwa tangannya tetap kotor meski dicuci berkali-kali \\
\hline G19 & Ragu apakah pintu rumah ditinggalan terbuka \\
\hline $\mathrm{G} 20$ & Ragu telah mematikan Kompor \\
\hline
\end{tabular}

Data gejala di atas diberikan nilai bobot oleh psikolog, agar bisa diimplementasikan ke dalam metode Dempster Shafer. Adapun nilai bobot tersebut terlihat pada tabel 3.

Table 3. Data Bobot Gejala

\begin{tabular}{cccc}
\hline Kode & \multicolumn{3}{c}{ Nilai Bobot } \\
& W & C & O \\
\hline G01 & 0.8 & 0.8 & 0.8 \\
G02 & 0.8 & 0.8 & 0.8 \\
G03 & 0.7 & 0.7 & 0.7 \\
G04 & 0.8 & 0.8 & 0.8 \\
G05 & 0.8 & 0.8 & 0.8 \\
G06 & 0.7 & 0.6 & 0.7 \\
G07 & 0.8 & 0.8 & 0.8 \\
G08 & 0.7 & 0.7 & 0.7 \\
G09 & 0.8 & 0.7 & 0.6 \\
G10 & 0.8 & 0.6 & 0.6 \\
G11 & 0.4 & 0.3 & 0.2 \\
G12 & 0.3 & 0.6 & 0.8 \\
G13 & 0.8 & 0.5 & 0.4 \\
G14 & 0.8 & 0.3 & 0.2 \\
G15 & 0.2 & 0.8 & 0.3 \\
G16 & 0.3 & 0.8 & 0.4 \\
G17 & 0.4 & 0.8 & 0.4 \\
G18 & 0.8 & 0.3 & 0.3 \\
G19 & 0.2 & 0.8 & 0.4 \\
\hline
\end{tabular}

Nidia Enjelita Saragih, Copyright (C2021, MIB, Page 51 
JURNAL MEDIA INFORMATIKA BUDIDARMA

Volume 5, Nomor 1, Januari 2021, Page 48-57

ISSN 2614-5278 (media cetak), ISSN 2548-8368 (media online)

Available Online at https://ejurnal.stmik-budidarma.ac.id/index.php/mib

DOI 10.30865/mib.v5i1.2533

\begin{tabular}{cccc}
\hline Kode & \multicolumn{3}{c}{ Nilai Bobot } \\
& W & C & O \\
\hline G20 & 0.2 & 0.8 & 0.2 \\
\hline
\end{tabular}

Referensi: Dra. Irna Minauli, M.Si

\section{HASIL DAN PEMBAHASAN}

Pada aplikasi hasil impelementasi metode Dempster Shafer dalam diagnosa OCD ini, user diminta untuk menjawab sejumlah pertanyaan terkait gejala yang dialami. Jawaban ini akan dihitung menggunakan metode Dempster Shafer berdasarkan bobot nilai yang diberikan pakar. Berikut merupakan flowchart yang menggambarkan proses perhitungan dalam metode Dempster Shafer.

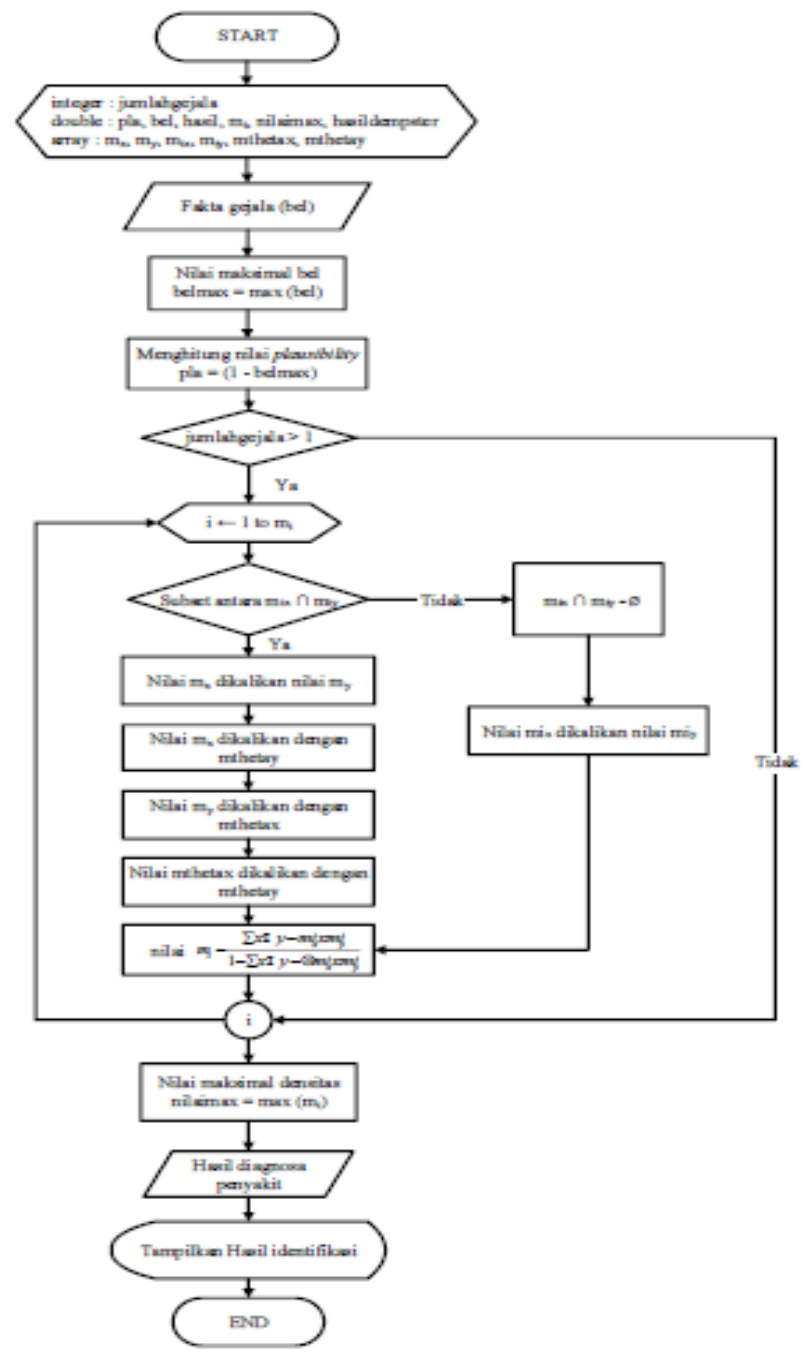

Gambar 2. Flowchart Dempster Shafer

Misalkan seorang pasien memiliki gejala: Meyakini bahwa dirinya terkontaminasi oleh orang lain, mengecek suatu pekerjaan secara berulang, dan ragu apakah pintu rumah ditinggalan terbuka.

Gejala 1 : Meyakini bahwa dirinya terkontaminasi oleh orang lain(G13).

$$
\begin{array}{ll}
\mathrm{m} 1\{\mathrm{O}, \mathrm{W}\} & =0.8 \\
\Theta & =1-0,8 \\
& =0.2
\end{array}
$$

Gejala 2 : Mengecek suatu pekerjaan secara berulang (G17)

$$
\begin{array}{ll}
\mathrm{m} 2\{\mathrm{C}\} & =0.8 \\
\Theta & =1-0,8 \\
& =0.2
\end{array}
$$

Dengan munculnya 2 gejala di atas, maka harus dilakukan penghitungan densitas baru untuk beberapa kombinasi (m3). Untuk memudahkan perhitungan maka himpunan-himpunan bagian yang terbentuk dimasukkan 


\section{JURNAL MEDIA INFORMATIKA BUDIDARMA}

Volume 5, Nomor 1, Januari 2021, Page 48-57

ISSN 2614-5278 (media cetak), ISSN 2548-8368 (media online)

Available Online at https://ejurnal.stmik-budidarma.ac.id/index.php/mib DOI 10.30865/mib.v5i1.2533

ke dalam tabel. Kolom pertama diisi dengan gejala yang pertama (m1). Sedangkan baris pertama diisi dengan gejala yang kedua $(\mathrm{m} 2)$. Sehingga diperoleh nilai $\mathrm{m}_{3}$ sebagai hasil kombinasi $\mathrm{m} 1$ dan $\mathrm{m} 2$.

Tabel 4. Aturan Kombinasi m3

\begin{tabular}{llllll}
\hline & & $\{\mathrm{C}\}$ & 0.8 & $\Theta$ & 0.2 \\
\hline$\{\mathrm{O}, \mathrm{W}\}$ & 0.8 & $\Theta$ & 0.64 & $\{\mathrm{O}, \mathrm{W}\}$ & 0.16 \\
$\Theta$ & 0.2 & $\{\mathrm{C}\}$ & 0.16 & $\Theta$ & 0.04 \\
\hline
\end{tabular}

Karena tidak adanya irisan antara $\{\mathrm{P} 1, \mathrm{P} 4\}$ dan $\{\mathrm{P} 2\}$ maka diperoleh $\{\Theta\}$ pada baris kedua kolom kedua dan nilainya diperoleh dari $0,2 \times 0,4$. Demikian pula $\{\mathrm{P} 2\}$ pada baris kedua kolom ketiga merupakan irisan antara $\{\mathrm{P} 2\}$ baris kedua kolom pertama dengan $\{\Theta\}$ pada baris pertama kolom ketiga dan nilainya diperoleh dari $0,8 \times 0.4$. Sehingga dapat dihitung.

$$
\begin{aligned}
& \mathrm{m} 3(0, C)=\frac{0.16}{1-0.64}=0.44 \\
& \mathrm{~m} 3(\mathrm{~W})=\frac{0.16}{1-0.64}=0.44 \\
& \mathrm{~m} 3(\theta)=\frac{0.04}{1-0.64}=0.111
\end{aligned}
$$

Jika kemudian terdapat gejala lain yaitu : ragu apakah pintu rumah ditinggalan terbuka (m4 $\{\mathrm{C}\}$ ), maka harus dilakukan perhitungan untuk densitas baru m5.

Untuk memudahkan perhitungan maka himpunan-himpunan akan dibuat ke dalam bentuk tabel. Kolom pertama berisi semua himpunan bagian pada m3 sebagai fungsi densitas. Sedangkan baris pertama berisi semua himpunan bagian pada ragu apakah pintu rumah ditinggalan terbuka dengan $\mathrm{m} 4$ sebagai fungsi densitas. Sehingga diperoleh nilai $\mathrm{m} 5$ sebagai hasil $\mathrm{m}$ kombinasi

$$
\begin{aligned}
& \mathrm{m} 4\{\mathrm{C}\}=0,8 \\
& \mathrm{~m}(\Theta)=1-0,8=0,2
\end{aligned}
$$

Tabel 5. Aturan Kombinasi m5

\begin{tabular}{cccccc}
\hline & & $\{\mathrm{C}\}$ & 0.8 & $\Theta$ & 0.2 \\
\hline$\{\mathrm{O}, \mathrm{W}\}$ & 0.444 & $\Theta$ & 0.355 & $\{\mathrm{O}, \mathrm{W}\}$ & 0.088 \\
$\{\mathrm{C}\}$ & 0.444 & $\{\mathrm{C}\}$ & 0.355 & $\{\mathrm{C}\}$ & 0.088 \\
$\Theta$ & 0.111 & $\{\mathrm{C}\}$ & 0.088 & $\Theta$ & 0.022 \\
\hline
\end{tabular}

Sehingga dapat dihitung:

$$
\begin{gathered}
\mathrm{m} 5(0, \mathrm{~W})=\frac{0.088}{1-0.355}=0.136 \\
\mathrm{~m} 5(\mathrm{C})=\frac{0.088+0.088+0.352}{1-0.355}=0.818 \\
\mathrm{~m} 5(\theta)=\frac{0.022}{1-0.355}=0.033
\end{gathered}
$$

Berdasarkan langkah-langkah diatas maka dapat disimpulkan nilai densitas (m) baru sesuai gejala baru.

Tabel 6. Kesimpulan dalam menentukan nilai densitas (m)

\begin{tabular}{ccc}
\hline No & \multicolumn{2}{c}{ Nilai Densitas } \\
& Densitas $(\mathrm{m})$ & Nilai \\
\hline 1 & $\mathrm{~m} 1(\mathrm{O}, \mathrm{W})$ & 0.8 \\
& $\mathrm{~m} 1(\Theta)$ & 0.2 \\
2 & $\mathrm{~m} 2(\mathrm{C})$ & 0.8 \\
& $\mathrm{~m} 1(\Theta)$ & 0.2 \\
3 & $\mathrm{~m} 3(\mathrm{O}, \mathrm{W})$ & 0.44 \\
& $\mathrm{~m} 3(\mathrm{C})$ & 0.44 \\
& $\mathrm{~m} 3(\Theta)$ & 0.2 \\
4 & $\mathrm{~m} 4(\mathrm{C})$ & 0.8 \\
& $\mathrm{~m} 1(\Theta)$ & 0.2 \\
5 & $\mathrm{~m} 5(\mathrm{O}, \mathrm{W})$ & 0.136 \\
\hline
\end{tabular}


ISSN 2614-5278 (media cetak), ISSN 2548-8368 (media online)

Available Online at https://ejurnal.stmik-budidarma.ac.id/index.php/mib

DOI 10.30865/mib.v5i1.2533

\begin{tabular}{ccc}
\hline No & \multicolumn{2}{c}{ Nilai Densitas } \\
& Densitas $(\mathrm{m})$ & Nilai \\
\hline & $\mathrm{m} 3(\mathrm{C})$ & 0.818 \\
$\mathrm{~m} 3(\Theta)$ & 0.033 \\
\hline
\end{tabular}

Tabel 6 menunjukkan bagaimana proses perhitungan aturan kombinasi awal sampai aturan kombinasi terakhir berdasarkan gejala yang dipilih, maka dapat disimpulkan bahwa nilai densitas paling tinggi adalah $\mathrm{C}$, yaitu Obsessive Compulsive Disorder tipe Checking dengan nilai densitasnya yaitu 0,818 x 100\% $=81 \%$.

\subsection{Implementasi Program}

Adapun implementasi tampilan antarmuka sistem pakar diagnosa penyakit Obsessive Compulsive Dissorder dengan Metode Dempster Shafer adalah sebagai berikut.

\section{a. Antarmuka Halaman Awal}

Halaman awal adalah halaman yang pertama kali muncul saat user mengakses alamat sistem. Implementasi antarmuka halaman awal sistem dapat digambarkan seperti pada Gambar 3.

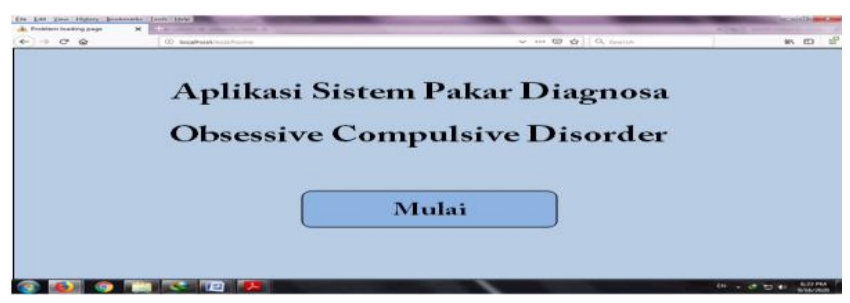

Gambar 3. Tampilan Halaman Awal

Halaman ini akan menjadi halaman yang pertama sekali muncul saat dijalankan. User diminta menekan tombol "Mulai" untuk masuk ke halaman selanjutnya.

\section{b. Antarmuka Halaman Identitas.}

Setelah user menekan tombol "Masuk" , tampilan berikutnya yang muncul adalah tampilan isian data diri. User diminta untuk mengisi data seperti nama, usia, dan jenis kelamin, sebelum memulai diagnosa.

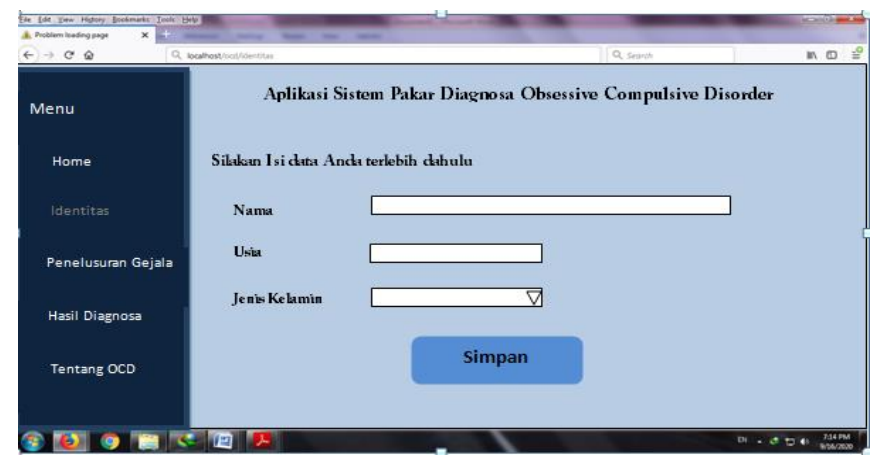

Gambar 4. Tampilan Identitas

\section{c. Antarmuka Halaman Penelusuran}

Selanjutnya, user diminta untuk mengisikan checkbox yang bersesuaian dengan gejala yang dialami oleh user sesuai terlihat pada gambar 5 .

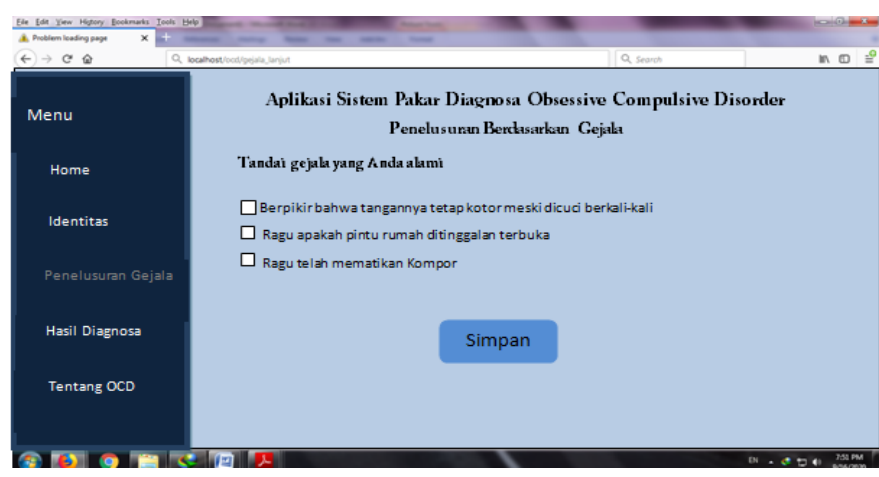

Gambar 5. Tampilan Halaman Penelusuran 
ISSN 2614-5278 (media cetak), ISSN 2548-8368 (media online)

Available Online at https://ejurnal.stmik-budidarma.ac.id/index.php/mib DOI 10.30865/mib.v5i1.2533

Setiap halaman hanya menampilkan beberapa gejala, user harus menggeser halaman untuk sampai pada halaman akhir dari penelusuran gejala, agar bisa mendapatkan hasil diagnosa.

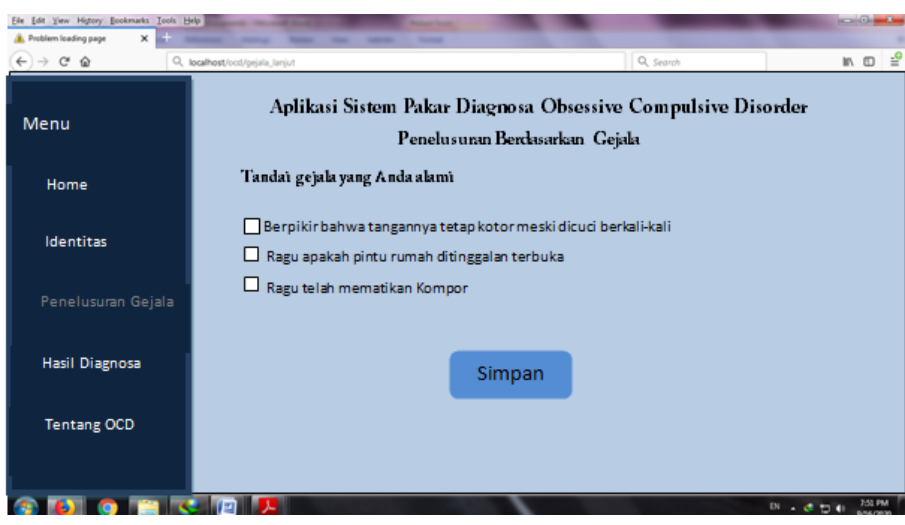

Gambar 6. Tampilan Halaman Akhir Penelusuran

d. Antarmuka Halaman Hasil Diagnosa

Gambar 7 berikut menampilkan hasil diagnosa dari gejala yang diinputkan oleh user.

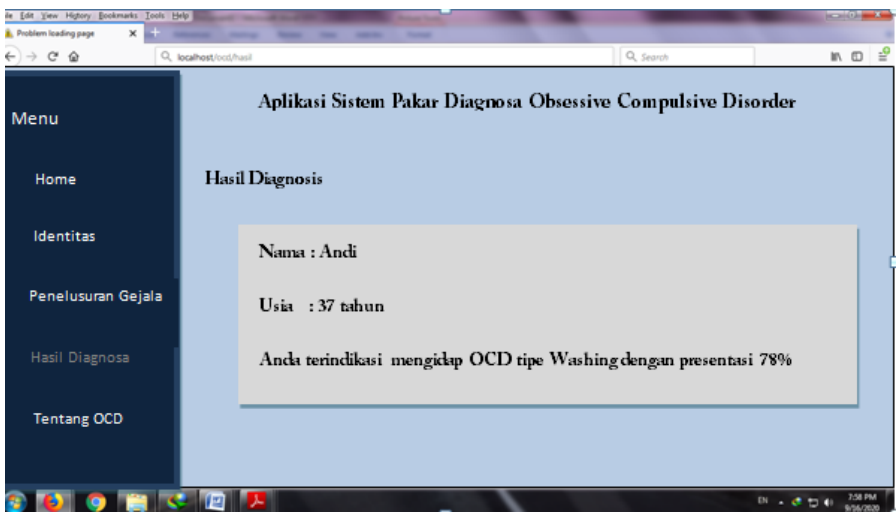

Gambar 7. Tampilan Halaman Hasil Diagnosa

Hasil yang ditampilkan dalam bentuk presentase yang merupakan nilai yang dihasilkan dari perhitungan menggunakan metode Dempster Shafer pada data gejala yang diisi oleh user. Nilai presentase ini akan menjadi patokan seberapa besar kemungkinan seorang user mengidap OCD sehingga user bisa memutuskan untuk mendapatkan penanganan psikologis sebelum penyakit semakin parah.

\section{e. Antarmuka Halaman Tentang}

Tampilan pada gambar 8 dimaksudkan untuk memberikan gambaran informasi mengenai penyakit OCD.

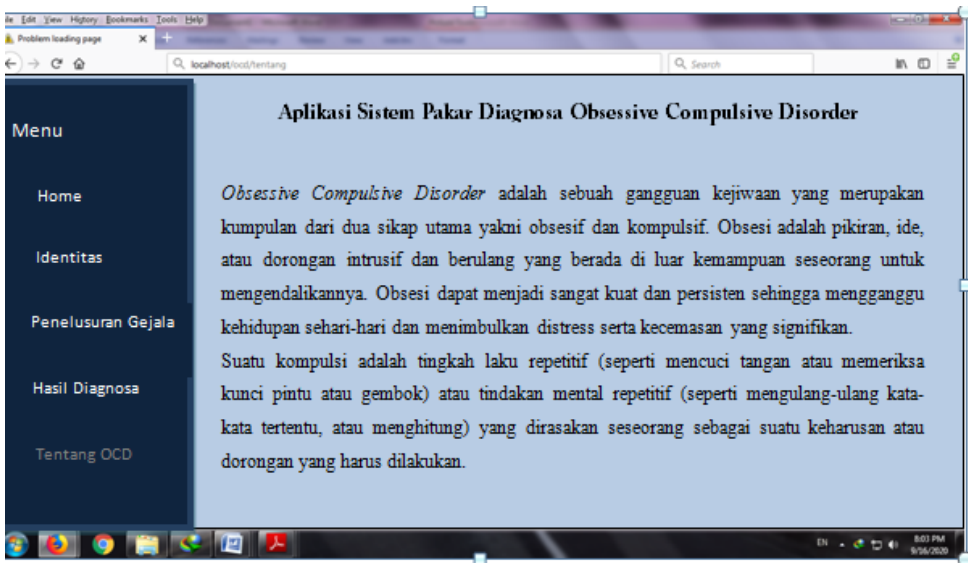

Gambar 8. Tampilan Halaman Tentang

\subsection{Pengujian}

Pengujian cross check (verifikasi pakar) ini dilakukan dengan cara membandingkan hasil akhir dari proses yang dihasilkan suatu aplikasi / program dengan pengetahuan yang bersumber dari ahli / pakar terkait penelitian diatas 
ISSN 2614-5278 (media cetak), ISSN 2548-8368 (media online)

Available Online at https://ejurnal.stmik-budidarma.ac.id/index.php/mib

DOI 10.30865/mib.v5i1.2533

untuk mendapatkan keakuratan hasil dari sistem pakar yang telah dibangun untuk seterusnya digunakan oleh user.

Tabel 7. Data Pengujian

\begin{tabular}{|c|c|c|c|c|}
\hline Pengujian & Gejala yang dipilih & $\begin{array}{c}\text { Hasil oleh } \\
\text { pakar }\end{array}$ & $\begin{array}{l}\text { Hasil oleh } \\
\text { sistem }\end{array}$ & $\begin{array}{l}\text { Kesim } \\
\text { pulan }\end{array}$ \\
\hline 1 & $\begin{array}{l}\text {-Muncul dorongan melakukan kegiatan berulang } \\
\text {-Meyakini bahwa dirinya terkontaminasi oleh orang } \\
\text { lain } \\
\text {-Berpikir bahwa tangannya tetap kotor meski dicuci } \\
\text { berkali-kali }\end{array}$ & $\begin{array}{l}\text { OCD tipe } \\
\text { Washing }\end{array}$ & $\begin{array}{l}80 \% \text { OCD } \\
\text { tipe } \\
\text { washing }\end{array}$ & Sesuai \\
\hline 2 & $\begin{array}{l}\text { - Memburuknya hubungan sosial } \\
\text { - Kecemasan yang muncul berasal dari dalam diri, } \\
\text { bukan pengaruh dari luar } \\
\text { - Terus-menerus mengecek kunci pintu }\end{array}$ & $\begin{array}{l}\text { OCD tipe } \\
\text { Checking }\end{array}$ & $\begin{array}{l}74,8 \% \\
\text { OCD tipe } \\
\text { Checking }\end{array}$ & Sesuai \\
\hline 3 & $\begin{array}{l}\text {-Munculnya dorongan, kekhawatiran, dan bayangan- } \\
\text { bayangan yang terus mengganggu yang menyebabkan } \\
\text { kegelisahan } \\
\text {-Menghabiskan waktu lebih dari satu jam untuk } \\
\text { melakukan hal yang berulang } \\
\text { - Muncul dorongan agresif yang mengerikan( misalnya } \\
\text { melukai anak-anak atau berteriak di tempat ibadah) }\end{array}$ & $\begin{array}{l}\text { OCD tipe } \\
\text { Washing }\end{array}$ & $\begin{array}{l}61,2 \% \\
\text { OCD tipe } \\
\text { Washing }\end{array}$ & Sesuai \\
\hline 4 & $\begin{array}{l}\text { - Tidak sedang berada di bawah pengaruh obat-obatan } \\
\text { - Berusaha menekan atau menghilangkan gangguan } \\
\text { kecemasan dengan melakukan kegiatan berulang } \\
\text { - Muncul kebutuhan untuk memastikan segala benda } \\
\text { dalam kondisi khusus(misalnya susunan benda mesti } \\
\text { simetris, dan berjumlah genap/ganjil) }\end{array}$ & $\begin{array}{l}\text { OCD tipe } \\
\text { Counting }\end{array}$ & $\begin{array}{l}84,5 \% \\
\text { OCD tipe } \\
\text { Counting }\end{array}$ & Sesuai \\
\hline
\end{tabular}

Berdasarkan pengujian yang dilakukan di atas, diperoleh kesesuaian kesimpulan antara analisa pakar dengan analisa yang dilakukan oleh sistem. Dengan demikian, sistem yang berjalan telah berjalan dengan baik dan menghasilkan kesimpulan sesuai dengan yang diharapkan.

\section{KESIMPULAN}

Berdasarkan penelitian yang telah dilakukan, dengan menggunakan data gejala yang didapat dari pakar dihasilkan sebuah aplikasi sistem pakar deteksi Obsessive Compulsive Disorder yang telah berjalan dengan baik. Ada 3 tipe Obsessive Compulsive Disorder yang mampu dikenali oleh sistem ini, yakni tipe washing, checking, dan ordering. Bobot pada masing-masing gejala yang didapat dari pakar dihitung menggunakan metode Dempster Shafer untuk menghasilkan nilai persentasi indikasi seseorang mengidap OCD dengan terlebih dahulu menginput gejala yang dialaminya. Nilai persentasi yang dihasilkan dengan metode Dempster Shafer ini, telah diuji secara cross-checking dengan analisa yang dilakukan oleh pakar dan diperoleh kesesuaian. Hal ini berarti metode Dempster Shafer cocok untuk digunakan dalam sistem pakar deteksi Obsessive Compulsive Disorder. Kesesuaian yang diperoleh dari pengujian juga berarti sistem dianggap telah berhasil menyimpan pengetahuan yang dimiliki oleh pakar dengan baik. Oleh karena itu, nilai yang didapat ini cukup akurat untuk dijadikan parameter bagi user dalam membantu memutuskan untuk mengambil langkah penanganan. Sistem yang dihasilkan tidak menyediakan pengetahuan mengenai terapi atau pengobatan yang dilakukan terhadap gangguan Obsessive Compulsive Disorder. Sebab hal ini membutuhkan observasi menyeluruh yang hanya bisa dilakukan melalui konsultasi langsung dengan seorang psikolog. Padapenelitian selanjutnya diharapkan peneliti mengembangkan sistem pakar deteksi penyakit mental lain yang saat ini banyak diderita oleh masyarakat, agar bisa tertangani lebih cepat.

\section{UCAPAN TERIMAKASIH}

Ucapan terimakasih peneliti sampaikan kepada Direktorat Riset dan Pengabdian Masyarakat (DRPM) yang telah mendanai penelitian ini.

\section{REFERENCES}

[1] Alwisol, Psikologi Kepribadian (Edisi Revisi). 2014.

[2] A. P. Maba and F. Tarbiyah, "Paradoxical Intervention Dalam Bimbingan Dan," J. Ilm. Couns., vol. 7, no. 2, pp. 99 


\section{JURNAL MEDIA INFORMATIKA BUDIDARMA}

Volume 5, Nomor 1, Januari 2021, Page 48-57

ISSN 2614-5278 (media cetak), ISSN 2548-8368 (media online)

Available Online at https://ejurnal.stmik-budidarma.ac.id/index.php/mib

DOI 10.30865/mib.v5i1.2533

109, 2017.

[3] F. L. K. Nida, "Zikir Sebagai Psikoterapi Dalam Gangguan Kecemasan Bagi Lansia,” J. Bimbing. Konseling Islam, vol. 5, no. 1, pp. 133-150, 2014.

[4] American Psychiatric Association, Diagnostic and Statistical Manual of Mental Disorders Fifth Edition, DSM-5, 5th ed. Arlington: VA, American Psychiatric Association., 2013.

[5] W. A. Puspitosari, "Terapi Kognitif dan Perilaku pada Gangguan Obsesif Kompulsif,” J. Mutiara Med., 2016.

[6] C. Suryaningrum, "Cognitive Behavior Therapy (Cbt) Untuk Mengatasi Gangguan Obsesif Kompulsif," J. Ilm. Psikol. Terap., 2013.

[7] R. Dwisaptani, . H., and . N., "Dinamika Penderita Gangguan Obsesif Kompulsif Kebersihan," J. Ilm. Sos. dan Hum., vol. 5, no. 1, pp. 7-24, 2011.

[8] F. Fakhruddiana, "Penghayatan dan Zikir Surah An-Nas untuk Mengurangi Gejala Obsessive-Compulsive Disorder ( OCD )," pp. 1-16, 2006.

[9] N. A. Hasibuan, H. Sunandar, S. Alas, and M. T. Informatika, "Gajah Menggunakan Metode Certainty," no. 1, pp. 2939, 2017.

[10] K. Kirman, A. Saputra, and J. Sukmana, "Sistem Pakar Untuk Mendiagnosis Penyakit Lambung Dan Penanganannya Menggunakan Metode Dempster Shafer," Pseudocode, vol. 6, no. 1, pp. 58-66, 2019.

[11] M. D. Sinaga and N. S. B. Sembiring, "Penerapan Metode Dempster Shafer Untuk Mendiagnosa Penyakit Dari Akibat Bakteri Salmonella," CogITo Smart J., vol. 2, no. 2, p. 94, 2016.

[12] S. Angelia and D. Jollyta, "Metode Dempster Shafer untuk Mendeteksi Penyakit Mental Disorder: Skizofrenia dan Psikotik," JMApTeKsi, vol. 1, no. 2, pp. 104-109, 2019.

[13] F. F. C. Triara Puspitasari, Boko Susillo, "Implementasi Metode Dempster-Shafer Dalam Sistem Pakar Diagnosa Anak Tunagrahita Berbasis Web," Jurnal Ilmiah Teknik Informatika. 2016.

[14] S. Lestanti and A. D. Susana, "Jurnal Antivirus, Vol. 10," vol. 10, no. 2, pp. 69-77, 2016.

[15] G. Y. Swara, M. Kom, and Y. Pebriadi, "REKAYASA PERANGKAT LUNAK PEMESANAN TIKET BIOSKOP Jurnal TEKNOIF ISSN : 2338-2724,” J. TEKNOIF, vol. 4, no. 2, pp. 27-39, 2016

[16] F. P. RANI, D. M. KHAIRINA, and H. R. HATTA, "Berprestasi Menggunakan Metode Multi Objective Optimization on the Basis of Ratio Analysis Decision Support System To Select Pandega Scout Achievement Using Multi Objective Optimization on the Basis of Ratio Analysis," J. Teknol. Inf. dan Ilmu Komput., vol. MESRAN., R, no. 2, pp. 155-162, 2019. 